\title{
Cardiac and respiratory standstill during sleep
}

\author{
T. R. D. SHAW, R. J. M. CORRALL, AND I. A. CRAIB \\ From the Departments of Cardiology and Medicine, Western General Hospital, Edinburgh
}

SUMMARY An obese man, with an attack of myocardial ischaemia, developed arrhythmias only when he was asleep. Episodes of sinus bradycardia occurred progressing to atrioventricular block and sinus arrest. These changes in the cardiac rhythm coincided with periods of sleep apnoea.

We describe a patient with myocardial ischaemia who had both cardiac and respiratory arrhythmias during sleep.

\section{Case report}

The patient, a 47-year-old train driver, was admitted to the coronary care unit at 0500 hours. He had been awakened from sleep with sweating, nausea, and a severe chest tightness, which had lasted for 2 hours.

The patient was obese. He was in sinus rhythm and there were no abnormal cardiac signs. The blood pressure was $170 / 110 \mathrm{mmHg}$ and remained high. The electrocardiogram, initially normal, later developed $\mathrm{T}$ wave inversion in leads $\mathrm{I}, \mathrm{aVL}, \mathrm{V} 5$, and V6. Serum levels of the cardiac enzymes remained normal, and an attack of myocardial ischaemia was diagnosed. No further episodes of pain occurred during his hospital stay and the only complications were the respiratory and cardiac arrhythmias described below. He was never given any digitalis, diuretic, or hypnotic drugs.

\section{RESPIRATORY AND CARDIAC}

\section{ARRHYTHMIAS}

After admission the patient slept for a short period. During this sleep it was noticed that his respiratory pattern became irregular, with long periods of apnoea interrupted by short spells of snorting breaths. In the apnoeic periods his heart rate progressively slowed reaching as low as $18 / \mathrm{min}$, and the PR interval lengthened to $0.49 \mathrm{~s}$. During the longer apnoeic pauses complete atrioventricular block and then sinus arrest occurred, with slow idioventricular escape beats. When he was wakened the respiration and cardiac rhythm immediately became normal. The electrocardiogram and ventilation abnormalities reappeared at intervals during further episodes of sleep that day and night.
The respiratory and cardiac arrhythmias are illustrated in the Figure. Since all effective breaths produced snorting noises the respiratory pattern was recorded using a phonocardiogram microphone taped lightly over the larynx. As sleep deepened over 10 to 20 minutes the respiratory rhythm became irregular with progressively longer apnoeic periods. No chest or abdominal movements were seen until the end of an interval of apnoea when, for a few seconds, very small and ineffective movements of the chest occurred, followed by the abrupt onset of noisy, deep respirations. During 9 consecutive respiratory cycles the apnoeic period averaged 63 seconds (range 27-83 s) and the period of noisy breathing averaged 10.5 seconds (range 9-14 s).

Arterial blood samples from a Medicut catheter in a radial artery were taken at the beginning and end of apnoeic periods. The results of the arterial blood gas analysis are given in the Table.

By the 4th day after admission the respiratory arrhythmia persisted but only a sinus bradycardia occurred during apnoea.

\section{ELECTROENCEPHALOGRAM}

An electroencephalogram was recorded during sleep and showed the abrupt onset of an arousal pattern 2 to 3 seconds before the end of an apnoea, indicating that the patient had to wake himself up in order to breath adequately.

\section{LUNG FUNCTION STUDIES}

The chest $x$-ray, $\mathrm{FEV}_{1}, \mathrm{FVC}$, and CO transfer factor were normal. Arterial blood samples taken with the patient asleep, awake, and after hyperventilation had $\mathrm{PO}_{2}$ levels of $5 \cdot 1,8 \cdot 8$, and $11 \cdot 7 \mathrm{kPa}$, respectively, showing that some hypoventilation was present during wakefulness as well as in sleep. $\mathrm{CO}_{2}$ rebreathing response and breathholding time were normal. The ear, nose, and throat examination disclosed slight septal deviation but the upper air- 


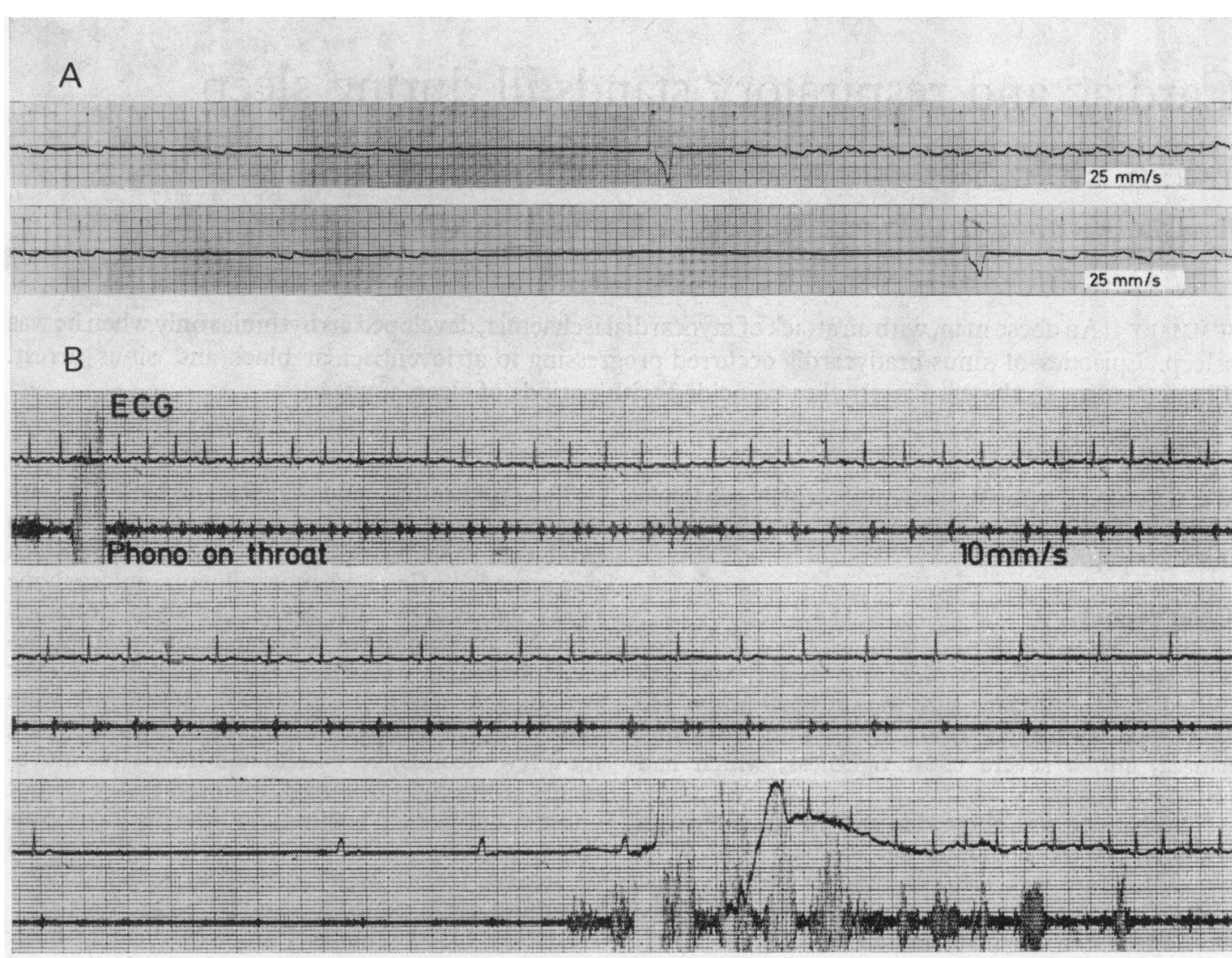

Fig. (A) Cardiac arrhythmias recorded at the end of two periods of prolonged sleep apnoea; (B) simultaneous recordings $(10 \mathrm{~mm} / \mathrm{s})$ of the electrocardiogram and the respiratory pattern. All effective breaths produced snoring sounds and were recorded with a microphone on the throat. The strips are continuous.

Table Changes in 3 paired sets of arterial blood samples taken at the beginning and end of apnoeic periods during sleep

\begin{tabular}{|c|c|c|}
\hline & Beginning of apnoea & End of apnoea \\
\hline $\begin{array}{l}\mathrm{Po}_{2}(\mathrm{kPa}) \\
\quad(\text { normal range } 12 \cdot 6-13 \cdot 3) \\
\mathrm{Pco}_{3}(\mathrm{kPa}) \\
\quad(\text { normal range } 4 \cdot 5-6 \cdot 0) \\
\mathrm{H}^{+} \text {concentration }(\mathrm{nmol} / \mathrm{l}) \\
\quad \text { (normal range } 45-38)\end{array}$ & $\begin{array}{l}6 \cdot 8,7 \cdot 0,6 \cdot 1 \\
\text { mean } 6 \cdot 6 \\
5 \cdot 7,5 \cdot 6,5 \cdot 9 \\
\text { mean } 5 \cdot 7 \\
39,41,41 \\
\text { mean } 40 \\
(p H 7 \cdot 40)\end{array}$ & $\begin{array}{l}6 \cdot 4,6 \cdot 9,5 \cdot 3 \\
\text { mean } 6 \cdot 2 \\
6 \cdot 7,6 \cdot 7,6 \cdot 5 \\
\text { mean } 6 \cdot 6 \\
42,45,45 \\
\text { mean } 44 \\
(p H 7 \cdot 36)\end{array}$ \\
\hline
\end{tabular}

Conversion factor; $1 \mathrm{kPa} \approx 7.5 \mathrm{mmHg}$.

ways were considered adequate and palatal closure was complete.

\section{OBESITY}

Although tall $(187 \mathrm{~cm})$ and broad the patient was considerably obese. He weighed $138 \mathrm{~kg}$ and, as assessed from the Desirable Weight tables of the
Metropolitan Life Insurance Company, he was $48 \mathrm{~kg}$ overweight. His total body water, measured by hydrogen isotope, was 60.4 litres; in a normal person this would correspond to a body weight of $102 \mathrm{~kg}$, indicating his excessive weight was $36 \mathrm{~kg}$ (Widdowson and Dickerson, 1964).

\section{PAST HISTORY OF SLEEP DISORDER}

The patient's wife had been 'too well aware' of the patient's noisy, irregular breathing during sleep. She said that the abnormal pattern had started immediately after an attack of 'severe glandular fever' eight years earlier. During this illness the patient had been feverish and for a few days had been confused and delirious. Since this illness he had tended to fall asleep at inappropriate times. While sitting at a table during a meal he could fall asleep with food still in his mouth. He stated that he often found sleep was not satisfying and he still felt tired each morning. 


\section{PROGRESS}

The patient was put on a weight reducing diet and supervised at regular follow-up visits. Six months after admission he had lost $27 \mathrm{~kg}$. He had no cardiac symptoms and reported feeling very much fitter and alert. He now enjoyed his sleep and his wife expressed her delight at his quieter and less restless nights. He was readmitted for overnight observation six months after his first admission. The respiratory pattern during sleep still showed some irregularity, varying between very small and very deep respiratory movements but the overall ventilation was considerably improved. There were no periods of total apnoea and intervals of small amplitude chest movements never lasted beyond 10 seconds. Heart rate varied in a cyclical fashion between 60 and 42 beats per minute. There was no change in the PR interval and no sinoatrial arrest. During deep sleep $\mathrm{Po}_{2}$ was $10.2 \mathrm{kPa}(95.5 \%$ saturation), while awake $11.4 \mathrm{kPa}(97.7 \%)$, and after hyperventilation at $15.69 \mathrm{kPa}(98.8 \%): \mathbf{P C O}_{2}$ was $5.18,5.05$, and $3.06 \mathrm{kPa}$, respectively.

\section{Discussion}

Our patient suffered from periods of 'sleep apnoea'. This is an uncommon but distinctive form of sleep disturbance first described by Gastaut et al. (1965). This type of periodic breathing is associated with the Pickwickian syndrome and other hypersomnias, but can also occur in otherwise normal non-obese persons who complain of poor sleeping (Guilleminault et al., 1975a). The features and pathogenesis of sleep apnoea have recently been reviewed by Guilleminault et al. (1976).

This patient's distinct obesity, daytime somnolence, and periodic breathing are features of the Pickwickian syndrome (Burwell et al., 1956), but he did not have the characteristic polycythaemia, cor pulmonale, or the abnormal response to inhaled carbon dioxide. The distinct improvement after weight reduction indicates that his obesity was an important factor. However, the persistence of a milder respiratory abnormality in sleep after weight loss suggests that an additional central nervous system abnormality was also present. The sudden start to his disturbed sleep after his confusional state raises the possibility that he may have had an attack of encephalitis which damaged the brainstem centres. A past history of encephalitis has been found in some cases of chronic hypoventilation (Fishman, 1972).

The cardiac arrhythmia was produced by the conjunction of two factors: the attack of myocardial ischaemia and the hypoxia during sleep apnoea. On admission it always coincided with the onset of sleep apnoea but disappeared after a few days, though the respiratory abnormality persisted. After the acute phase of the ischaemia he continued to show some fluctuation in heart rate during the respiratory cycles in sleep, with a slower sinus rate during apnoea. A vicious cycle is likely to have been created with a falling heart rate and worsening hypoxia increasingly compromising already ischaemic sinoatrial and atrioventricular nodes. Kryger et al. (1974) described a patient with sleep apnoea who had transient bouts of atrial fibrillation during apnoea. Tilkian et al. (1975) recorded sinus and ventricular arrest and ventricular tachycardia in patients with sleep apnoea.

This case shows that coronary heart disease may combine with sleep apnoea to produce a major arrhythmia. Such arrhythmias may be one cause of the not infrequent sudden deaths in patients with the Pickwickian syndrome (MacGregor et al., 1970). Sleep apnoea has also been postulated as a possible cause of cot deaths (Guilleminault et al., 1975b). Sleep apnoea should be suspected when there is a history of unsatisfying, restless sleep interrupted by bouts of snoring or in any patient with a hypersomnia syndrome. Hypnotic and sedative drugs should be avoided in these cases since they may precipitate a respiratory crisis which can be fatal (Hishikawa et al., 1972; Guilleminault et al., 1975a). Weight loss is the best treatment but occasional cases require tracheostomy (Kryger et al., 1974, Coccagna et al., 1972) which has an immediate effect in correcting the respiratory and cardiac abnormalities.

We thank Dr G. J. R. McHardy, Dr H. R. A. Townsend, and Dr R. H. Smith for their help and advice.

\section{References}

Burwell, C. S., Robin, E. D., Whaley, R. D., and Bickelmann, A. G. (1956). Extreme obesity associated with alveolar hypoventilation-a Pickwickian syndrome. American fournal of Medicine, 21, 811-818.

Coccagna, G., Mantovani, M., Brignani, F., Parchi, C., and Iugaresi, E. (1972). Tracheostomy in hypersomnia with periodic breathing. Bulletin de Physio-pathologie Respiratoire, 8, 1217-1227.

Fishman, A. P. (1972). The syndrome of chronic alveolar hypoventilation. Bulletin de Physio-pathologie Respiratoire, 8, 971-980.

Gastaut, H., Tassinari, C. A., and Duron, B. (1965). Etude polygraphique des manifestations episodiques (hypniques et respiratoires) diurnes et nocturnes du syndrome de Pickwick. Revue Neurologique, 112, 568-579.

Guilleminault, C., Eldridge, F. I., Simmon, F. B., and Dement, W. C. (1975a). Sleep apnoea syndrome: can it induce hemodynamic change? Western fournal of Medicine, 123, 7-16. 
Guilleminault, C., Peraita, R., Souquet, M., and Dement, W. C. (1975b). Apneas during sleep in infants: possible relationship with sudden infant death syndrome. Science, 190, 677-679.

Guilleminault, C., Tilkian, A., and Dement, W. C. (1976). The sleep apnea syndromes. Annual Review of Medicine, 27, 465-484.

Hishikawa, Y., Furuya, E., Wakamatsu, H., and Yamamoto, J. (1972). A polygraphic study of hypersomnia with periodic breathing and primary alveolar hypoventilation. Bulletin de Physio-pathologie Respiratoire, 8, 1139-1151.

Kryger, M., Quesney, L. P., Holder, D., Gloor, P., and MacLeod, P. (1974). The sleep deprivation syndrome of the obese patient. American fournal of Medicine, 56, 531-539.
MacGregor, M. I., Block, A. J., and Ball, W. C., Jr. (1970). Serious complications and sudden death in the Pickwickian syndrome. fohns Hopkins Medical fournal, 126, 279-295. Tilkian, A., Guilleminault, C., Schroeder, K. L., Lehrman, K., Simmons, F. B., and Dement, W. C. (1975). Sleep induced apnoea syndrome: reversal of serious arrhythmias after tracheostomy. Circulation, 52, 131.

Widdowson, E. M., and Dickerson, J. W. T. (1964). Mineral Metabolism, Vol. 2, p. 1. Ed. by C. L. Comar and F. Bronner. Academic Press, New York.

Requests for reprints to Dr T. R. D. Shaw, Department of Cardiology, Western General Hospital, Crewe Road, Edinburgh. 